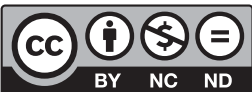

Estudos Teológicos foi licenciado com uma Licença Creative Commons Atribuição - NãoComercial - SemDerivados 3.0 Não Adaptada

http://dx.doi.org/10.22351/et.v58i2.3499

\title{
OS PRIMÓRDIOS DA RELIGIÃO POLITIZADA: A TEOLOGIZAÇÃO DE CONCEITOS POLÍTICOS IMPERIAIS NO ISRAEL ANTIGO ${ }^{1}$
}

\author{
The Beginnings of Politicized Religion: \\ The Theologization of Imperial Political Concepts in Ancient Israel
}

\begin{abstract}
Konrad Schmid ${ }^{2}$
Resumo: Religiões são produtos políticos, sociológicos e culturais. A religião dos antigos Israel e Judá como refletida na Bíblia Hebraica/Antigo Testamento foi especialmente moldurada pelas suas interações com as ideologias imperiais do antigo Oriente Próximo, ou seja, os pensamentos políticos dos impérios do primeiro milênio antes da nossa era. $\mathrm{O}$ livro de Deuteronômio adaptou a estrutura básica de tratados assírios de vassalo $\left(9^{\circ}\right.$ a $7^{\circ}$ séculos antes da nossa era). No entanto, os transformou radicalmente: em vez de requerer que nações subjugadas teriam que ser absolutamente leais ao rei da Assíria, o livro de Deuteronômio exige que seja exclusivamente leal ao seu Deus. O chamado Documento Sacerdotal (P) na Torá reflete a ideologia do Império Persa $\left(6^{\circ}\right.$ a $4^{\circ}$ séculos antes da nossa era): os persas administravam seu império de um jeito pluralístico e bastante tolerante, permitindo às nações subjugadas viverem de acordo com sua própria religião e costumes. Neste caso, P estava em concordância com a ideologia imperial dos persas: textos como Gênesis 10 exibem uma concepção do mundo no qual toda nação deve ter sua própria língua, cultura e religião. Reconhecer o pano de fundo político de teologias bíblicas ajuda na compreensão de textos e livros bíblicos, pois muitas vezes interpretaram Deus de um modo inspirado pelo pensamento político da época na qual foram compostos.
\end{abstract}

Palavras-chave: Ideologia imperial. Israel e Judá. Antigo Oriente Próximo. Deuteronômio. Documento Sacerdotal.

1 O artigo foi recebido em 07 de novembro de 2018 e aprovado em 09 de novembro de 2018 com base nas avaliações dos pareceristas ad hoc.

Este ensaio é uma versão levemente abreviada e atualizada de SCHMID, Konrad. Anfänge politikförmiger Religion: Die Theologisierung politisch-imperialer Begriffe in der Religionsgeschichte des antiken Israel als Grundlage autoritärer und toleranter Strukturmomente monotheistischer Religionen. In: LIEDHEGENER, Antonius et al. (ed). Religion - Wirtschaft - Politik: Forschungszugänge zu einem aktuellen transdisziplinären Feld. Zürich; Baden-Baden, 2011. p. 161-177. Tradução: Luís Marcos Sander, com financiamento do PROEX/CAPES.

2 Doutor em Teologia e livre-docente em Antigo Testamento pela Universidade de Zurique. Professor titular de Ciência Veterotestamentária e História da Religião do Judaísmo Primitivo na Universidade de Zurique, Suíça. Contato: konrad.schmid@theol.uzh.ch 
Abstract: Religions are historical, political, sociological and cultural products. The religion of ancient Israel and Judah as reflected in the Hebrew Bible/Old Testament was particularly shaped by its interactions with the imperial ideologies of the ancient Near East, that is the political thoughts of the empires of the 1st millennium BCE. The book of Deuteronomy adapted the basic structure of Assyrian vasall treaties (9th to 7th centuries $\mathrm{BCE})$. However, it transformed them radically: Instead of claiming that subdued nations need to be absolutely loyal to the Assyrian king, the book of Deuteronomy demands that Israel is exclusively loyal to its God. The so-called Priestly Document (P) in the Torah reflects the ideology of the Persian empire (6th to 4th centuries BCE): The Persians administered their empire in a pluralistic and relatively tolerant way, allowing the subdued nations to live according to their own religions and customs. In this case, the Priestly Document $(\mathrm{P})$ was in agreement with the imperial ideology of the Persians: Texts like Genesis 10 exhibit a notion of the world in which every nation is meant to have its own language, culture, and religion. Acknowledging the political background of biblical theologies helps to understand the texts and books of the Bible, as they often interpreted God in ways that were inspired by the political thinking of the era in which they were composed.

Keywords: Imperial Ideology. Israel and Judah. Ancient Near East. Deuteronomy. Priestly Document.

\section{Introdução}

Existe uma predileção em discutir a relação entre religião e política com base em escritos e textos de pensadores, filósofos e teólogos como Agostinho de Hipona, Tomás de Aquino, Nicolau Maquiavel, Martim Lutero, Thomas Hobbes, John Locke, Jean-Jacques Rousseau, Karl Marx, Carl Schmitt, Eric Voegelin e outros.

Essa abordagem a um campo temático altamente complexo como esse é, naturalmente, possível, legítima e proveitosa. Pode, porém, ser útil voltar para trás desses pensadores cujos nomes são tão conhecidos até aquelas figuras anônimas que, na história da literatura, teologia e filosofia da Bíblia inauguraram a condição de possibilidade da interação posterior entre religião e política por terem começado a interpretar a relação entre Deus e Israel em terminologias e concepções políticas, que, por sua vez, tomaram de empréstimo das potências imperiais da época - ou seja, pelo fato de começarem a conceber a religião, de certo modo, de maneira "politizada".

Ao fazer isso, depara-se com a surpreendente constatação de que, no tocante às conexões históricas de fundamentação da religião bíblica na Antiguidade, encontra-se, de certa forma, o contrário daquilo que Carl Schmitt acreditou poder observar em relação à Modernidade, a saber, que "todos os conceitos marcantes da moderna teoria do Estado são conceitos teológicos secularizados"3. Não precisamos discutir e menos ainda decidir aqui se as reflexões de Schmitt são acertadas ou não. No Israel antigo se podem, em todo caso, constatar correlações claras entre conceitos marcantes

3 ,alle prägnanten Begriffe der modernen Staatslehre sind säkularisierte theologische Begriffe“; SCHMITT, Carl. Politische Theologie: Vier Kapitel zur Lehre von der Souveränität. 8. ed. Berlin, 2004. p. 43. 
das expressões intelectuais de sua religião e ideologias políticas correspondentes das respectivas potências hegemônicas, de modo que, para esse estágio da formação da religião bíblica, torna-se plausível a ideia de uma teologização de conceitos políticos ${ }^{4}$ que adquiriu grande importância em termos dos efeitos que produziu na história.

Em seus traços básicos, essa percepção da teologização de conceitos políticos na religião de modo algum é revolucionária, mas passa a fazer sentido com base na circunstância de que as noções de ordens e estruturas da esfera numinosa foram, em todas as culturas da humanidade, concebidas em certa correlação com as realidades terrenas. Essa é a particula veri [partícula de verdade] na crítica da religião desde Ludwig Feuerbach até Sigmund Freud, que, aliás, também combina com um elemento fundamental no pensamento de Karl Barth e, já neste sentido, de modo algum tem a conotação de algo teologicamente ilegítimo: a religião é, nas palavras de Barth, "obra humana"s. As religiões são claramente sistemas historicamente construídos e culturalmente determinados e, neste sentido, não pode surpreender que sejam decisivamente influenciadas pelas respectivas realidades políticas de seu período histórico.

No caso da religião bíblica, isso pode ser demonstrado com suficiente clareza no tocante a algumas noções fundamentais. No que segue se abordará primeiramente a articulação histórico-cultural do Israel antigo com o Antigo Oriente, a qual é, aliás, a condição de possibilidade de tais processos de recepção. Depois seguem três estudos de caso brevemente esboçados que mostram, com base na transposição subversiva do sistema contratual assírio, do distanciamento em relação à tradição jurídica neobabilônica e da recepção positiva da ideologia imperial persa, como surgiram as noções bíblicas - que na sequência se tornaram muito influentes - de aliança, direito divino e teocracia. ${ }^{6}$ Essa contribuição será concluída com uma breve avaliação.

\section{A articulação histórico-cultural do Israel antigo no Antigo Oriente}

O Israel antigo não é um corpo estranho, uma entidade sui generis, e sim um subconjunto do Antigo Oriente, estando articulado de muitas formas com seus vizinhos em termos de história cultural e intelectual. Na atualidade, essa percepção pode ser considerada communis opinio [opinião comum, consenso]. Que isso seja assim é algo que se pode mostrar apenas com base nas realidades geográficas e históricas elementares do Israel antigo. O Israel antigo é, por um lado, do ponto de vista espacial, um Estado pequeno dentro do Antigo Oriente e, por outro lado, do ponto de vista temporal, um temporão. Israel aparece no cenário mundial, em seus primeiros traços, não antes do ano 1000 a.C., enquanto que as grandes civilizações desenvolvidas na Mesopotâmia e no Egito são pelo menos dois mil anos mais antigas.

4 Quanto a isso, cf. ASSMANN, Jan. Herrschaft und Heil: Politische Theologie in Altägypten, Israel und Europa. München, 2000.

5 BARTH, Karl. Die Kirchliche Dogmatik: Die Lehre vom Wort Gottes - Prolegomena zur Kirchlichen Dogmatik I,2 §§ 16-18. Studienausgabe. Zürich, 1993. v. 4, p. 358.

${ }^{6}$ Quanto a isso, cf. pormenores em SCHMID, Konrad. Literaturgeschichte des Alten Testaments: Eine Einführung. 2. ed. Darmstadt, 2014. 
Seguindo o egiptólogo James Henry Breasted, designa-se a área geográfica cultivável entre o Egito e a Mesopotâmia, unida pelo Levante, como "Crescente Fértil". É perfeitamente claro e previsível que a história de Israel jamais tenha se desenrolado em splendid isolation [esplêndido isolamento], mas tenha sido profundamente marcada pelas interações com o mundo da Antiguidade da época, principalmente com o Egito e a Mesopotâmia. Por isso, do ponto de vista histórico, também não se deveria falar do entorno ou mundo circundante do Israel antigo, pois este não era o centro desse mundo da Antiguidade, e sim uma parte dele - provavelmente, de início, uma parte bastante sem importância.

$\mathrm{Na}$ pesquisa bíblica, esse entrelaçamento nem sempre foi percebido em grau suficiente. Ele se arraigou claramente na consciência dessa pesquisa no fim do século XIX e início do XX. O século XIX foi marcado pelas grandes descobertas arqueológicas no Egito e na Mesopotâmia, e esse entusiasmo fascinou toda uma geração de jovens biblistas dentre os quais surgiu a chamada "escola da história das religiões"7. Dela faziam parte figuras como Wilhelm Bousset, Johannes Weiss, Hugo Gressmann, Hermann Gunkel e outros. Eles estavam convencidos de que só se poderia entender a Bíblia adequadamente dentro do contexto histórico-cultural dela. No início dos anos 20 do século XX, contudo, o rumo da discussão mudou decisivamente e a teologia dialética, que então despertava em torno de Karl Barth, empurrou a escola da história das religiões cada vez mais para a periferia teológica. Então, após a Segunda Guerra Mundial, a teologia dialética conseguiu se estabelecer como corrente principal na teologia protestante de língua alemã, e isso também se refletiu incisivamente nas disciplinas exegéticas do Antigo e Novo Testamentos.

O paradigma explanatório - predominante até poucas décadas antes - de derivação de noções bíblicas da história das culturas e religiões desapareceu quase inteiramente. O que passou para o primeiro plano agora foi a ausência de analogias da fé bíblica. Na sequência, os biblistas do Antigo Testamento encontraram a distinção fundamental entre teologia natural e teologia da revelação - central na teologia dialética - também na história das religiões do Oriente Próximo. Na esteira dessa concepção, o Israel antigo era tido como uma entidade toda especial no Antigo Oriente. Israel era, usando a terminologia da teologia dialética, totalmente diferente de seus vizinhos, que, assim, acabaram passando para o segundo plano do interesse.

No tocante à articulação do Israel antigo e da Bíblia com seu entorno em termos de história da religião e da cultura, em meados do século XX se estava, a rigor, mais uma vez aquém do nível de conhecimento da escola da história das religiões na virada do século XIX para o XX.

Isso só voltou a mudar fundamentalmente nos últimos 30 anos. São vários os fatores que levaram a uma nova sensibilidade histórico-religiosa e histórico-cultural na ciência bíblica.

7 LÜDEMANN, Gerd; ÖZEN, Alf. Religionsgeschichtliche Schule. In: Theologische Realenzyklopädie. Berlin: De Gruyter, 1997. v. 28, p. 618-624. 
Primeiramente devem-se mencionar os progressos feitos na arqueologia na terra de Israel: desde os anos 80 do século XX, a ciência bíblica dispõe de numerosas descobertas e informações novas sobre como se deve imaginar Israel na época bíblica, e essas descobertas confirmam substancialmente a ideia de que em todo caso o paradigma da descontinuidade que conseguiu se estabelecer na esteira da teologia dialética e acentuou tão fortemente as diferenças entre Israel e seu entorno não pode estar correto como tal.

Além disso, a situação global da teologia se alterou decisivamente: na esteira da Segunda Guerra Mundial, a teologia dialética se tornara uma espécie de corrente principal, mas desde os anos 70 do século XX a teologia se tornou de novo muito mais pluralista, o que se mostrou, particularmente no que diz respeito à ciência bíblica, em um certo movimento de descolonialização intelectual.

E, por fim, também se percebeu que o paradigma romântico que definia os autores da Bíblia como gênios religiosos também não é historicamente sustentável: na maioria e decerto também em suas mais importantes partes a Bíblia não remonta a indivíduos dotados do Espírito que redigiram seus textos tomados por zelo religioso, como se costumava supor na época dos fundadores da ciência bíblica, no início do século XIX. Antes, partes consideráveis da Bíblia devem ser um produto de escribas para escribas. Hoje em dia se diria que, em partes substanciais, ela não é literatura de edificação, nem literatura popular, mas apresenta um discurso erudito sobre corpos de conhecimentos da época.

A influência histórico-cultural das potências do Antigo Oriente sobre Israel deixou marcas diversas. No primeiro milênio a.C, os assírios (séculos IX-VII a.C.), os babilônios (VII/VI), os persas (VI-IV) e os gregos (IV-II) se alternaram no exercício da hegemonia sobre o Levante. Basicamente, pode-se observar que a diminuição da opressão militar, que no Império Assírio ainda representou o elemento central na garantia do poder imperial, trouxe consigo uma culturalização do poder, que assegurava a existência de um império de forma alternativa. ${ }^{8}$ Em consonância com isso, o domínio estrangeiro dos persas é visto de modo muito mais positivo no Antigo Testamento do que o assírio, principalmente porque a culturalização do poder persa tinha uma orientação substancialmente mais pluralista e aberta para a autonomia local do que, mutatis mutandis, a propaganda assíria tinha previsto.

Com base na situação das descobertas amplamente disseminadas, não se deve duvidar da possibilidade fundamental da existência de contatos culturais vastos, também em termos geográficos, no Oriente Próximo da Antiguidade ${ }^{9}$ : há descobertas de fragmentos que mostram que em Amarna, no Egito, está documentado o mito babilônico de Adapa, em Ugarit, no norte da Síria, se conhecia a epopeia de Atrahasis, e em Megido, no norte de Israel, lia-se a epopeia de Gilgamesh. Na ilha egípcia de

8 Cf. MÜNKLER, Herfried. Imperien: Die Logik der Weltherrschaft - vom Alten Rom bis zu den Vereinigten Staaten. Berlin, 2005. p. 87s.

9 Cf. HOROWITZ, Wayne; OSHIMA, Takayoshi; SANDERS, Seth. A Bibliographical List of Cuneiform Inscriptions from Canaan, Palestine/Philistia, and the Land of Israel. Journal of the American Oriental Society, v. 122, p. 753-766, 2002. 
Elefantina está documentada uma versão aramaica da inscrição iraniana de Behistun. Os contatos culturais dentro do Antigo Oriente eram tão estreitos que a posição intermediária de Israel e sua dependência política quase contínua das respectivas grandes potências no Eufrates e no Nilo (dentro do chamado "Crescente Fértil") fazem com que seja não apenas possível, e sim mais do que provável que as concepções culturais e religiosas fundamentais e correntes fossem conhecidas em Israel e recebidas com distanciamento ou aprovação.

Portanto a literatura israelita da Antiguidade deve ser interpretada em seu contexto do Antigo Oriente - e livre dos entraves pseudoteológicos da disputa em torno da influência da religião babilônica sobre o Antigo Testamento do início do século $\mathrm{XX} .{ }^{10} \mathrm{~A}$ originalidade da Bíblia não reside na ausência de analogias para seus materiais, e sim nas interpretações e transformações destes que, entretanto, só podem ser captados adequadamente lançando-se um olhar para além da Bíblia. Isso será exposto brevemente a partir dos três estudos de caso mencionados.

\section{A transposição da concepção assíria de contrato para Deus}

Com o início da supremacia assíria no Oriente Próximo, que atingiu seu auge inicial em meados do século VIII a.C. e se manteve até o final do século VII, antes de retroceder diante dos neobabilônios, Israel e Judá ficaram sob a influência de uma grande potência imperial que exerceu uma pressão política, militar e, mais e mais, religiosa e cultural extraordinariamente grande. Os assírios podem ser considerados a primeira das potências que buscou decididamente o controle político, econômico e militar sobre o mundo antigo conhecido na época.

Nessa mesma época, o século VIII a.C., situa-se, segundo conhecimentos mais recentes, a primeira formação de um certo grau de estatalidade em Israel e Judá, de modo que, neste tocante, Israel e Judá se encontraram desde o início sob a influência assíria. Pode-se ir até um passo adiante: provavelmente foi a influência histórico-cultural de Assur que desencadeou o desenvolvimento que levou à estatalidade em Israel e Judá, que, por conseguinte, podem ser tidos como "estados secundários" ${ }^{11}$. No caso do Reino do Norte, Israel, contudo, foi também a pressão militar vinda de Assur que levou, depois de poucas décadas, em 722 a.C., ao ocaso desse jovem Estado. ${ }^{12}$ Mas, do ponto de vista da história das ideias, justamente essa catástrofe deve ter tido importância considerável: a reflexão sobre ela causou, em diversas áreas, uma formação intensiva de tradições. No Reino do Sul, Judá, foi então, no final do século VII, principalmente a formação e demarcação de uma identidade cultural e religiosa própria frente à potência assíria que se encontrava em declínio e, tradicionalmente, fazia uma propaganda intensiva que se refletiu na literatura contemporânea. Nessa época se formaram concepções decididamente antiassírias, que transpuseram as demonstra-

\footnotetext{
${ }^{10}$ Cf. LEHMANN, Reinhard G. Friedrich Delitzsch und der Babel-Bibel-Streit. Fribourg; Göttingen, 1994.

11 KNAUF, Ernst-Axel. Die Umwelt des Alten Testaments. Stuttgart, 1994. p. 80.

12 BECKING, Bob. The Fall of Samaria: An Historical and Archaeological Study. Leiden, 1992.
} 
ções de lealdade exigidas pelos assírios à relação com o próprio Deus. ${ }^{13}$ Neste tocante se deve mencionar especialmente o livro de Deuteronômio, que pode ser visto como uma recepção subversiva do sistema neoassírio de contratos ou tratados com vassalos.

Pode-se perceber isso na própria estrutura do Deuteronômio: ele consiste de uma introdução histórica, um corpo de leis e é concluído com o anúncio de bênção e maldição - dependendo de as estipulações contidas na parte principal serem cumpridas ou não. Essa estrutura corresponde aos contratos assírios com vassalos: se a potência assíria subjugava determinados povos, eles eram declarados vassalos e, substancialmente, obrigados a manter uma lealdade incondicional para com o rei assírio. Os vassalos leais recebiam a bênção do império, e os desleais se tornavam vítimas da máquina militar assíria.

E com o tema da lealdade já se menciona o ponto de vista decisivo, em termos de conteúdo, que define a assunção dessa concepção na Bíblia: também o livro de Deuteronômio exige uma lealdade incondicional, mas não ao rei assírio, e sim ao próprio Deus. Isso pode ser percebido com a maior clareza no chamado Shma Israel ("Ouve, Israel") em Deuteronômio 6.4s: "Ouve, Israel: Javé, nosso Deus, é um Javé. Amarás, pois, Javé, teu Deus, de todo o teu coração, de toda a tua alma e de toda a tua força". Especialmente a exigência de "amar" a Deus tem uma conotação política no mundo do Antigo Oriente: "amar" não é um termo emocional, e sim político, que designa a submissão fiel. Assim, nos contratos assírios de vassalagem também aparece de modo proeminente a exigência de "amar" o rei da Assíria. ${ }^{14} \mathrm{O}$ Deuteronômio afirma, em contraposição a isso, que essa forma de "amor", de lealdade absoluta, cabe somente a Deus.

Por causa desses contatos, duas coisas ficam claras: por um lado, pode-se perceber que o livro de Deuteronômio com sua teologia é inspirado pela Assíria. Por outro lado, porém, deve-se constatar que essa influência é, ao mesmo tempo, acompanhada de uma reinterpretação fundamental: a relação contratual é transposta do rei assírio para o próprio Deus. Exige-se lealdade a ele, e não mais ao rei. Naturalmente, divindades também se fazem presentes nos contratos assírios, mas lá sempre como garantes, e nunca como partes do contrato. No livro de Deuteronômio essa questão é diferente: o Israel antigo reinterpretou a relação contratual, fazendo dela um contrato entre Deus e seu povo. ${ }^{15}$

O potencial subversivo desse processo é evidente: ele é profundamente crítico para com o Império Assírio. Em consonância com isso, é plausível supor que, historicamente, ele só tenha se tornado possível em uma época em que o próprio Império

13 Essa percepção, que conta atualmente com grande apoio, já foi defendida nos anos 60 e 70 do século XX por WEINFELD, Moshe. Deuteronomy and the Deuteronomic School. Oxford, 1972, e outros. Quanto à discussão mais recente, cf., p. ex., STEYMANS, Hans Ulrich. Deuteronomy 28 and Tell Tayinat. Verbum et Ecclesia, v. 34, p. 1-13, 2013.

${ }^{14}$ Cf. MORAN, William L. The Ancient Near Eastern Background of the Love of God in Deuteronomy. Catholic Biblical Quarterly, v. 25, p. 77-87, 1963.

15 Cf. OTTO, Eckart. Treueid und Gesetz: Die Ursprünge des Deuteronomiums im Horizont neuassyrischen Vertragsrechts. Zeitschrift für altorientalische und biblische Rechtsgeschichte, v. 2, p. 1-52, 1996. 
Assírio já se encontrasse em declínio - portanto, na segunda metade do século VII a.C., antes de a capital, Nínive, ter caído em 622 a.C. - e não tivesse mais força para deter militarmente tais correntes dissidentes na periferia do império.

A avaliação teológica da interpretação imperial de Deus empreendida pelo livro de Deuteronômio pode ser posta de lado aqui, mas deve ser óbvio que ela tem ao menos traços ambivalentes. Mas ela é uma das mais elementares raízes do zelo religioso na história posterior do judaísmo, do cristianismo e do islã, que levou repetidamente adeptos dessas religiões a realizar, em dependência incondicional para com seu Deus, ações que decerto nem sempre resistem a uma avaliação crítica.

\section{O surgimento do direito divino}

Um dos componentes naturais da compreensão ocidental de direito é que o direito escrito é normativamente vinculante. Do ponto de vista histórico, contudo, particularmente com vistas à história do direito no Antigo Oriente e na Bíblia, é preciso constatar que as tradições jurídicas tinham primeiramente uma orientação mais descritiva e não apenas normativa, que elas não representavam diretrizes vinculantes, e sim subsídios para a resolução de questões jurídicas. ${ }^{16}$ É claro que, nas monarquias do Antigo Oriente, o rei era a instância legislativa última, e não um texto. Neste sentido, as coletâneas jurídicas do Antigo Oriente - Código de Hamurabi, Código de Lipit-Ishtar, Código de Ur-Nammu etc. - foram designadas de maneira equivocada pela pesquisa moderna como códigos, pois o termo código, em si, encerra a normatividade do que contém.

Seria mais correto designá-los como livros jurídicos que não oferecem uma cobertura completa da vida jurídica, mas descrevem, além de alguns casos gerais, também particularmente casos especiais complicados com base nos quais se pretende mostrar como a atividade jurisdicional pode se dar. $\mathrm{O}$ fato de esses textos não serem normativos por si mesmos pode ser percebido não só a partir de seu caráter eclético, mas também a partir da comparação com documentos processuais do Antigo Oriente que mostram que, às vezes, sentenças concretas podiam divergir claramente dos respectivos casos exemplares contidos nos livros jurídicos.

As coletâneas jurídicas na Bíblia Hebraica, que se encontram todas no Pentateuco, ainda mostram claramente em suas passagens mais antigas o enraizamento nessa tradição jurídica do Antigo Oriente. No chamado Código da Aliança (Êxodo 20-23) encontram-se compilações de preceitos jurídicos que regulamentam, de modo semelhante a seus equivalentes do Antigo Oriente, particularmente casos especiais e,

${ }^{16}$ Cf. GREENGUS, Samuel. Legal and Social Institutions of Ancient Mesopotamia. In: SASSON, Jack M. (Org.). Civilizations of the Ancient Near East. Peabody, Mass., 2000. v. 2. p. 469-484; MANTHE, Ulrich (Org.). Die Rechtskulturen der Antike: Vom Alten Orient bis zum Römischen Reich. München, 2003. 
como eles, decerto tinham sobretudo um caráter de orientação, e não de norma, na atividade jurisdicional. ${ }^{17}$

Ao mesmo tempo, porém, fica claro a partir das coletâneas jurídicas da Bíblia Hebraica que elas, em sua forma presente, revisada redacionalmente, distinguem-se fundamentalmente das do Antigo Oriente na medida em que estão redigidas como direito divino, e não como direito régio. $\mathrm{Na}$ Bíblia Hebraica, a instância legislativa é sempre Deus, e não o rei. Entre as questões incontestes na ciência bíblica está a percepção de que essa qualificação não se situa nos primórdios da história do direito da Bíblia Hebraica, mas só ocorreu paulatinamente por meio de revisões literariamente produtivas. Portanto ela não é inerente à substância textual das tradições jurídicas desde o início, mas foi acrescentada redacionalmente a ela aos poucos. ${ }^{18}$

Com a introdução e elaboração do direito divino na Bíblia Hebraica se dá, contudo, um passo importante: o direito assim configurado reivindica ser vinculante e normativo a partir de si mesmo. As razões disso podem ser identificadas historicamente. Por um lado, essa transferência de normatividade ${ }^{19}$ do rei para um corpo textual está enraizada na recepção subversiva - descrita na seção anterior - da teologia contratual neoassíria no Deuteronômio, dentro da qual o rei assírio foi substituído pelo Deus de Israel como soberano decisivo. Por outro lado, ela foi vigorosamente apoiada e ampliada pela perda do reinado próprio em Israel e Judá na sequência da conquista e destruição de Samaria em 722 a.C. pelos assírios e de Jerusalém em 587 a.C. pelos babilônios e - particularmente na sequência do segundo acontecimento - pela referência oposicional à tradição jurídica babilônica bastante ampla que via o rei como instância normativa por excelência. Com a eliminação do reinado se perdera em Israel, por assim dizer, a instância legislativa última. Encontrou-se uma substituição instalando a Deus na função de poder legislativo, que, porém - por razões compreensíveis -, não possui capacidades executivas concretas, não podendo, portanto, simplesmente fazer cumprir o direito instituído. Por isso não surpreende que o direito bíblico - depois de ascendido à condição de direito divino - disponha agora, em mais de 50\% dos preceitos jurídicos, de admoestações e fundamentações que conclamam incisivamente a que as disposições jurídicas sejam cumpridas. Sem um poder executivo externo, a própria consciência jurídica precisa fazer com que o direito seja reconhecido e cumprido.

Entretanto, o surgimento do direito divino ainda foi acompanhado por um outro processo: um direito classificado como direito divino não podia simplesmente ser

17 Cf. HOUTMAN, Cornelis. Das Bundesbuch: Ein Kommentar. Leiden, 1997; SCHWIENHORST-SCHÖNBERGER, Ludger. Das Bundesbuch (Ex 20,22-23,33): Studien zu seiner Entstehung und Theologie. Berlin; New York, 1990.

${ }^{18}$ Cf. OTTO, Eckart. „Um Gerechtigkeit im Land sichtbar werden zu lassen ... “: Zur Vermittlung von Recht und Gerechtigkeit im Alten Orient, in der Hebräischen Bibel und in der Moderne. In: MEHLHAUSEN, Joachim (Org.). Recht-Macht-Gerechtigkeit. Gütersloh, 1998. p. 107-145; SCHMID, Konrad, Divine Legislation in the Pentateuch in its Late Judean and Neo-Babylonian Context. In: DUBOVSKÝ, Peter et al. (Orgs.). The Fall of Jerusalem and the Rise of the Torah. Tübingen, 2016. p. 129-153.

${ }^{19}$ Cf. OTTO, Eckart. Exkarnation ins Recht und Kanonsbildung in der Hebräischen Bibel: Zu einem Vorschlag von Jan Assmann. Zeitschrift für altorientalische und biblische Rechtsgeschichte, v. 5, p. 99-110, 1999. 
mudado ou até revogado, mas só interpretado e explicado. A partir do momento em que o direito bíblico passou a dispor dessa qualificação, praticamente não restou outro caminho senão fazer as atualizações - naturalmente necessárias - do direito por meio de uma exegese intrabíblica. A atualização interpretativa do direito bíblico pode ser atestada claramente em diversos sentidos, de modo particularmente incisivo, por um lado, na retomada do Código da Aliança (Êx 20-23) no livro de Deuteronômio ${ }^{20}$ e, por outro, na retomada do Deuteronômio na Lei de Santidade (Lv 17-26) e de sua compensação com outros textos legais. ${ }^{21}$

Esse ponto é de importância decisiva para a tradição jurídica concebida como direito divino na Bíblia: ela é atribuída a Deus como autor e legislador, mas é, ao mesmo tempo, interpretada como condicionada pelo tempo, carente de atualização e passível de atualização. Pelo fato de que, no cânone bíblico, o texto e o comentário formam um conjunto, a dinâmica da interpretação já está implantada na própria Bíblia e tem, assim, ao menos o potencial de barrar desde o começo todo e qualquer fundamentalismo que poderia se derivar da concepção de direito divino e - como se pode, com facilidade, documentar historicamente - de fato se derivou dela.

\section{Teocracia}

Enquanto que a mais importante linha de recepção de elementos de tradições da potência assíria e babilônica no Israel da Antiguidade se caracterizavam por uma fundamental rejeição e subversão, pode-se observar o contrário disso no tocante ao Império Persa e sua supremacia sobre Israel. Os persas são vistos positivamente no Antigo Testamento. Assim, chama a atenção, por exemplo, o fato de que nos textos veterotestamentários não há um único oráculo sobre outros povos que se volte contra os persas. Essa circunstância se deve a que os persas, diferentemente dos impérios que os antecederam, praticavam uma política relativamente tolerante para com os povos que subjugavam e lhes concediam amplamente autonomia linguística, cultual, jurídica e cultural - decerto mais por causa da pura necessidade que as dimensões do império acarretavam do que a partir de reflexões (pré-)humanísticas. ${ }^{22}$

Essa ideologia imperial persa de um Estado pacificado formado por muitos povos mediante conservação das respectivas particularidades culturais e religiosas, expressa, por exemplo, na inscrição de Behistun de Dario I (TUAT I, 419-450), que - como mostram as descobertas de sua versão aramaica em Elefantina - também circulava como texto didático, foi retomada e apropriada positivamente em diversas concepções da literatura da época do domínio persa no Antigo Testamento, como, por exemplo, no Escrito Sacerdotal ou em Crônicas.

${ }^{20}$ Cf. LEVINSON, Bernard M. Deuteronomy and the Hermeneutics of Legal Innovation. New York, 1997.

${ }^{21}$ Cf. NIHAN, Christophe. From Priestly Torah to Pentateuch: A Study in the Composition of the Book of Leviticus. Tübingen, 2007.

${ }^{22}$ Cf. FREI, Peter; KOCH, Klaus. Reichsidee und Reichsorganisation im Perserreich. 2. ed. Fribourg; Göttingen, 1996. 
Esses escritos partem da premissa de que, com o domínio persa, a meta salutar da história de Javé com Israel - carregando nas tintas, nos moldes de uma "escatologia realizada" 23 - foi alcançada. Naturalmente, essa meta ainda precisa ser completada em diversos aspectos, mas basicamente a virada salvífica é tida como consumada. Essa posição não é, a rigor, outra coisa do que a recepção judaica da ideologia imperial oficial da Pérsia. Em Crônicas, leem-se Davi e Salomão em sua qualidade de iniciadores e construtores do templo praticamente como os modelos "proto-históricos" para Ciro e Dario, que, por um lado, possibilitaram a construção do templo (Ciro por meio de seu edito) e, por outro, mandaram executá-la (Dario).

Dentro da literatura contemporânea do Escrito Sacerdotal, essa imagem - inspirada pela época do domínio persa - de um mundo organizado se encontra na chamada tabela das nações em Gênesis 10, que descreve o repovoamento do mundo após o dilúvio (Gn 6-9). Ela dispõe de um refrão que descreve a ordem linguística e culturalmente diversificada do mundo:

Gênesis 10.5: [...] São estes os filhos de Jafé em suas terras, cada qual segundo sua língua, segundo seus clãs, em suas nações.

Gênesis 10.20: São estes os filhos de Cam segundo seus clãs, suas línguas, em suas terras, segundo suas nações.

Gênesis 10.31: São estes os filhos de Sem segundo seus clãs, suas línguas, em suas terras, segundo suas nações.

No marco dessa visão teocrática do mundo se situam também as designações conspícuas de soberanos estrangeiros como adoradores e até eleitos do Deus bíblico. Assim, por exemplo, o rei babilônico Nabucodonosor, que, afinal, destruiu Jerusalém e seu templo, é chamado de "servo" de Deus em Jeremias 25.9; 27.6; 43.10, e em Isaías 44.28 o rei persa Ciro é designado de "meu messias".

Do ponto de vista histórico, isso é compreensível não antes do que contra o pano de fundo da época do domínio persa, em que se desenvolveu a noção de que Deus também pode lançar mão de reis estrangeiros para governar o mundo. Essa concepção "teocrática" pressupõe o desprendimento da religião do Israel antigo de um pensamento orientado pelo próprio Estado e reinado bem como da ampliação universalizante desse pensamento, que só estão dados a partir da época do domínio persa.

\section{Avaliação}

A religião não é apenas um fator que se faz presente na política, mas, inversamente, também se pode dizer que a política é um fator presente na religião. Isso se aplica com destaque para as fases historicamente perceptíveis da formação da história da religião veterotestamentária, em especial, que definiram duradouramente as decisões teológicas fundamentais e as formas de expressão do posterior judaísmo e cristianismo.

${ }^{23}$ Realized eschatology é um termo cunhado por DODD, Charles Harold. The Parables of the Kingdom. London, 1935. p. 51, que, porém, o relaciona com a pregação de Jesus. 
Com vistas à percepção da Bíblia, essa circunstância deve ser inicialmente reconhecida e interpretada: do ponto de vista histórico, a Bíblia não é literatura de revelação, mas surgiu em um discurso muito próximo dos elementos do conhecimento e marcos de orientação das potências que na época eram relevantes em termos de história da cultura. Suas posições são contingentes do ponto de vista histórico e de conteúdo e devem ser avaliadas criticamente como tais. A teologia da Bíblia é, em partes específicas e efetivamente proeminentes, filha da política da época.

O que é particularmente digno de nota é que a religião bíblica, segundo as observações apresentadas, tem um cunho "imperial" em conteúdos substanciais de seus enunciados e noções - seja na rejeição do conteúdo, mas na assunção estrutural de concepções assírias ou babilônicas no âmbito contratual e jurídico, ou então na recepção positiva da ideologia política do Império Persa.

Do ponto de vista histórico, isso se deve inicialmente ao fato de que Deus, ao que tudo indica, foi concebido também no Israel antigo como id quo maius cogitari nequit (“aquilo em relação ao qual não se pode pensar nada maior”). Deve ser óbvio que, no mundo da Antiguidade, a instituição de um rei imperial se oferecia estruturalmente para a caracterização de uma concepção universal de Deus. Nas religiões monoteístas, particularmente em suas expressões ortodoxas, fundamentalistas e estritamente orientadas por uma Escritura, esse contexto interpretativo imperial se refletiu, às vezes, em estruturas ou formas de pensamento de cunho fortemente autoritário, que dificultam consideravelmente a possibilidade de negociação de alguns elementos tradicionais, mas relevantes para a política nessas religiões. "Antes, importa obedecer a Deus do que aos seres humanos" (At 5.29) - onde quer que esse argumento seja utilizado, ele tem suas raízes históricas últimas na história das ideias de cunho imperial do Israel antigo que marcou a ideia bíblica de Deus de diversas formas.

Seria, porém, um equívoco achar que essa tradição só merece e pode ser criticada. Em termos de conteúdo, essa descrição "imperial” de Deus acarreta, isto sim, uma ambivalência fundamental. Por um lado, Deus é, assim, o soberano incondicional a quem cabe obediência integral e em cujo nome se decide o que é verdadeiro e falso, mas, por outro lado, com isso também se relativiza fundamentalmente todo poder secular: o verdadeiro soberano do mundo é o próprio Deus, e todos os demais soberanos são apenas detentores indiretos de poder.

A mesma ambivalência caracteriza a interpretação da tradição jurídica do Antigo Testamento como direito divino. Por um lado, destaca-se com isso o caráter provisório de todo sistema jurídico secular, mas, por outro, dessa concepção resulta uma certa propensão à ideologia, pois naturalmente também o direito divino como tal é uma construção humana que pode se aproveitar dessa fachada metafísica.

É tarefa da crítica histórica da Bíblia esclarecer as condições de surgimento de concepções bíblicas como aliança, direito divino ou teocracia que se tornaram relevantes na história da interpretação, mas com isso submetê-las, ao mesmo tempo, 
a uma crítica objetiva e adequada. "A verdadeira crítica do dogma é sua história"24 isso se aplica aos dogmas pós-bíblicos e também às posições da própria Bíblia. Neste sentido, contudo, o processo da crítica deve ser mantido aberto em termos de resultado: mesmo que ideias e dogmas avulsos tenham de cair, outras também poderão se reafirmar. Em regra, porém, haverá de se constatar que não são as ideias e dogmas como tais, mas suas interpretações que proporcionarão os pontos de vista decisivos para perceber se elas são de valor ou dano duradouro. ${ }^{25}$

\section{Referências}

ASSMANN, Jan. Herrschaft und Heil: Politische Theologie in Altägypten, Israel und Europa. München, 2000.

BARTH, Karl. Die Kirchliche Dogmatik: Die Lehre vom Wort Gottes - Prolegomena zur Kirchlichen Dogmatik I,2 §§ 16-18. Studienausgabe. Zürich, 1993. v. 4.

BECKING, Bob. The Fall of Samaria: An Historical and Archaeological Study. Leiden, 1992. DODD, Charles Harold. The Parables of the Kingdom. London, 1935.

FREI, Peter; KOCH, Klaus. Reichsidee und Reichsorganisation im Perserreich. 2. ed. Fribourg; Göttingen, 1996. (OBO, 337).

GREENGUS, Samuel. Legal and Social Institutions of Ancient Mesopotamia. In: SASSON, Jack M. (Org.). Civilizations of the Ancient Near East. Peabody, Mass., 2000. v. 2.

HOUTMAN, Cornelis. Das Bundesbuch: Ein Kommentar. Leiden, 1997. (DMOA 24).

KNAUF, Ernst-Axel. Die Umwelt des Alten Testaments. Stuttgart, 1994.

LEVINSON, Bernard M. Deuteronomy and the Hermeneutics of Legal Innovation. New York, 1997. LÜDEMANN, Gerd; ÖZEN, Alf. Religionsgeschichtliche Schule. In: Theologische Realenzyklopädie. Berlin: De Gruyter, 1997. v. 28, p. 618-624.

MANTHE, Ulrich (Org.). Die Rechtskulturen der Antike: Vom Alten Orient bis zum Römischen Reich. München, 2003.

MORAN, William L. The Ancient Near Eastern Background of the Love of God in Deuteronomy. Catholic Biblical Quarterly, v. 25, p. 77-87, 1963.

NIHAN, Christophe. From Priestly Torah to Pentateuch: A Study in the Composition of the Book of Leviticus. Tübingen, 2007. (FAT, II/25).

OTTO, Eckart. „Um Gerechtigkeit im Land sichtbar werden zu lassen ...“: Zur Vermittlung von Recht und Gerechtigkeit im Alten Orient, in der Hebräischen Bibel und in der Moderne. In: MEHLHAUSEN, Joachim (Org.). Recht-Macht-Gerechtigkeit. Gütersloh, 1998. (VWGTh, 14). OTTO, Eckart. Exkarnation ins Recht und Kanonsbildung in der Hebräischen Bibel: Zu einem Vorschlag von Jan Assmann. Zeitschrift für altorientalische und biblische Rechtsgeschichte, v. 5, p. 99-110, 1999.

OTTO, Eckart. Treueid und Gesetz: Die Ursprünge des Deuteronomiums im Horizont neuassyrischen Vertragsrechts. Zeitschrift für altorientalische und biblische Rechtsgeschichte, v. 2, p. $1-52,1996$.

${ }^{24}$ STRAUSS, Daniel Friedrich. Die christliche Glaubenslehre in ihrer geschichtlichen Entwicklung und im Kampf mit der modernen Wissenschaft dargestellt. Tübingen, 1840. v. 1.

${ }^{25}$ Quanto a isso, cf. SCHMID, Konrad. Dogmatik als konsequente Exegese? Überlegungen zur Anschlussfähigkeit der historisch-kritischen Bibelwissenschaft für die Systematische Theologie. Evangelische Theologie, v. 77, p. 327-338, 2017. 
SCHMID, Konrad. Divine Legislation in the Pentateuch in its Late Judean and Neo-Babylonian Context. In: DUBOVSKÝ, Peter et al. (Orgs.). The Fall of Jerusalem and the Rise of the Torah. Tübingen, 2016. (FAT, 107).

. Anfänge politikförmiger Religion: Die Theologisierung politisch-imperialer Begriffe in der Religionsgeschichte des antiken Israel als Grundlage autoritärer und toleranter Strukturmomente monotheistischer Religionen. In: LIEDHEGENER, Antonius et al. (Orgs.). Religion - Wirtschaft - Politik: Forschungszugänge zu einem aktuellen transdisziplinären Feld. Zürich; Baden-Baden, 2011.

. Dogmatik als konsequente Exegese? Überlegungen zur Anschlussfähigkeit der historischkritischen Bibelwissenschaft für die Systematische Theologie. Evangelische Theologie, v. 77, p. 327-338, 2017.

Literaturgeschichte des Alten Testaments: Eine Einführung. 2. ed. Darmstadt, 2014.

SCHMITT, Carl. Politische Theologie: Vier Kapitel zur Lehre von der Souveränität. 8. ed. Berlin, 2004.

SCHWIENHORST-SCHÖNBERGER, Ludger. Das Bundesbuch (Ex 20,22-23,33): Studien zu seiner Entstehung und Theologie. Berlin; New York, 1990. (BZAW, 188).

STEYMANS, Hans Ulrich. Deuteronomy 28 and Tell Tayinat. Verbum et Ecclesia, v. 34, p. 1-13, 2013.

STRAUSS, Daniel Friedrich. Die christliche Glaubenslehre in ihrer geschichtlichen Entwicklung und im Kampf mit der modernen Wissenschaft dargestellt. Tübingen, 1840. v. 1.

WEINFELD, Moshe. Deuteronomy and the Deuteronomic School. Oxford, 1972. 